\title{
Mitochondrial encephalomyopathy: variable clinical expression within a single kindred
}

D Crimmins, J G L Morris, G L Walker, C M Sue, E Byrne, S Stevens, B Jean-Francis, C Yiannikas, R Pamphlett

\begin{abstract}
The clincal manifestations of mitochondrial encephalomyopathy are described in four generations of a single kindred. The age of onset of major neurological disturbance varied from 3-70 years. In some patients, deafness was the only manifestation; in others, recurrent bouts of status epilepticus associated with focal neurological deficits and headache, caused severe disability or death. Examples of all three adult forms of mitochondrial encephalomyopathy: MELAS, MERFF and Kearns Sayre syndrome, were represented within the kindred. Associated features included deafness, short stature, noninsulin-dependent diabetes mellitus, migraine, peptic ulceration and severe constipation. The nt 3243 A-G MELAS mutation was detected in two members of the kindred. This study highlights the diversity of clinical expression of a mitochondrial mutation within a single kindred.
\end{abstract}

(f Neurol Neurosurg Psychiatry 1993;56:900-905)

Mitochondrial encephalomyopathy takes many clinical forms and can begin at any age. The onset is from birth or early childhood in

Department of

Neurology, Westmead

Hospital, Sydney,

Australia

D Crimmins

J G L Morris

G L Walker

C M Sue

C Yiannikas

Department of

Neurology, St

Vincent's Hospital,

Melbourne, Australia

E Byrne

Department of

Neuropathology,

University of Sydney,

Sydney, Australia

$S$ Stevens

B Jean-Francis

R Pamphlett

Correspondence to:

Dr Morris, Department of

Neurology, Westmead

Hospital, Westmead

NSW 2145, Australia

Received 8 October 1991

and in final revised form

and in final revised

12 October 1992
Accepted 16 October 1992

\section{Methods}

Following identification of the proband, 14 of 24 living members of the family were examined by a neurologist (DC). CT scans were performed on 11 patients, audiometry on seven and EMG/nerve conduction studies on five. Blood glucose levels were measured in 10 patients, C-peptides, pyruvate and lactate levels in six patients. CSF pyruvate and lactate levels were measured in two patients.

Open muscle biopsies were performed in eight patients. These were examined with standard light microscopy, histochemistry and electron microscopy. The histochemical studies were performed on fresh frozen muscle obtained, under local anaesthesia, from the vastus lateralis or the deltoid muscle. Routine stains were performed including $\mathrm{H}$ and $\mathrm{E}$; myofibrillar ATPase at $\mathrm{pH} \mathrm{9.4,} \mathrm{4.6}$ and 4.3 ; NADH; succinate dehydrogenase; PAS; Sudan black; phosphorylase; Gomorri trichrome and acid phosphatase. Staining for cytochrome $\mathrm{C}$ oxidase was performed on some of the later biopsies.

The biochemical studies were performed using standard methods. ${ }^{9}$ A total of 250 muscle biopsies from a referral centre for neuromuscular disease, which were normal on routine histochemical stains, were used as controls. The mean and two standard deviations for each assay were calculated. Total cell DNA was extracted from muscle biopsy specimens in all cases. Polymerase Chain Reaction (PCR) amplification and restriction enzyme analysis was used to probe for $\mathrm{mt}$ DNA mutations. The nucleotide (nt) 3243A$G$ mutation (MELAS) ${ }^{10}$ was sought using a primer pair $\mathrm{B}_{\mathrm{L}} \mathrm{F}$ corresponding to $\mathrm{nt}$ $2826-2849$ of the light strand and $\mathrm{ND} 2_{\mathrm{H}}$ corresponding to nt 5459 to 5482 of the heavy strand. The alternative MELAS mutation (A-G ntpos 11084) and the MERRF mutation (A-G ntpos 8344) were probed for as previously described. ${ }^{11} 12$ PCR amplified DNA fragments were examined by electrophoresis on Agarose gels for the fragments in the region of $\mathrm{mt}$ DNA associated with the MELAS and MERRF mutations.

Aliquots of purified mt DNA fragments were digested with the appropriate restriction enzyme at 37 degrees overnight (ApaI for nt 3243[MELAS], Bg11 for nt 8344[MERRF]). Digested DNA was electrophoresed on agarose gels, stained with ethidium bromide and photographed under UV light. The elec- 
trophoresed DNA was then transferred onto a nylon membrane, hybridised with the appropriate mt DNA fragment probe following random-prime labelling with ${ }^{32 p}$ dATP and visualised after exposure to Fuji Rx X-ray film at $70^{\circ} \mathrm{C}$.

\section{Results}

The family pedigree is shown in fig 1 and the clinical features are detailed in table $1(a, b$, c). It is apparent from these that the severity of the disease and the age of onset varied considerably within the kindred. We describe the case histories of a mother and two daughters, who were severely affected.

Table 1a Clinical, radiological and pathological features of the kindred

\begin{tabular}{|c|c|c|c|c|c|}
\hline Patient & $I V, 4$ & $I V, 5$ & $I V, 6$ & $I I I, 1$ & $I I I, 2$ \\
\hline \multirow{2}{*}{$\begin{array}{l}\text { Age at onset of major symptoms (y) } \\
\text { Age in } 1991 \text { of surviving members (y) } \\
\text { Age at death (y) }\end{array}$} & 13 & 3 & \multirow[b]{2}{*}{15} & \multirow[b]{2}{*}{58} & 40 \\
\hline & 19 & 11 & & & 41 \\
\hline \multicolumn{6}{|l|}{ Neurological features } \\
\hline Stroke-like episodes & + & + & - & - & + \\
\hline \multicolumn{6}{|l|}{ Status epilepticus: } \\
\hline Convulsive & - & + & - & - & + \\
\hline Non-convulsive & + & - & - & - & + \\
\hline Myoclonus & + & - & - & - & - \\
\hline Cerebellar ataxia & + & + & - & - & - \\
\hline Dementia & - & + & - & - & - \\
\hline Myopathy & - & - & - & - & - \\
\hline Headache/migraine & + & + & + & - & - \\
\hline Neuropathy & - & - & - & - & - \\
\hline \multicolumn{6}{|l|}{ Other clinical features } \\
\hline Short stature & + & - & - & - & + \\
\hline Deafness & + & - & + & + & + \\
\hline Diabetes & - & - & - & + & - \\
\hline Constipation & + & - & - & - & + \\
\hline Retinal pigmentation & - & + & - & - & - \\
\hline Cardiac arrhythmia & - & + & - & - & - \\
\hline Peptic ulceration & - & - & - & - & - \\
\hline \multicolumn{6}{|l|}{ CT Scan } \\
\hline Basal ganglia calcification & + & - & - & + & + \\
\hline Cortical hypodensities & + & + & - & - & + \\
\hline Cerebellar atrophy & - & - & - & - & + \\
\hline \multirow{2}{*}{\multicolumn{6}{|c|}{ Muscle Biopsy }} \\
\hline & & & & & \\
\hline Positive & + & & + & + & \\
\hline Not done & & + & & & + \\
\hline
\end{tabular}

Table $1 \mathrm{~b}$ Clinical, radiological and pathological features of the kindred

\begin{tabular}{|c|c|c|c|c|c|}
\hline Patient & III, 3 & $I I, 1$ & $I I, 3$ & $I I, 4$ & $I I, 5$ \\
\hline $\begin{array}{l}\text { Age at onset of major symptoms (y) } \\
\text { Age in } 1991 \text { of surviving members (y) }\end{array}$ & 56 & 30 & 70 & 60 & 55 \\
\hline Age at death $(y)$ & & 78 & 75 & 63 & \\
\hline \multicolumn{6}{|l|}{ Neurological features } \\
\hline Stroke-like episodes & - & - & - & + & + \\
\hline $\begin{array}{l}\text { Status epilepticus: } \\
\text { Convulsive }\end{array}$ & & & & & \\
\hline Convulsive & - & - & - & + & - \\
\hline Non-convulsive & - & - & - & - & - \\
\hline Myoclonus & - & - & - & - & - \\
\hline Cerebellar ataxia & - & - & - & - & + \\
\hline Dementia & - & - & - & + & + \\
\hline Myopathy & - & - & - & - & + \\
\hline Headache/migraine & - & - & - & + & - \\
\hline Neuropathy & - & - & - & - & + \\
\hline \multicolumn{6}{|l|}{ Other clinical features } \\
\hline Short stature & - & - & - & - & - \\
\hline Deafness & + & + & + & + & + \\
\hline Diabetes & - & + & + & + & + \\
\hline Constipation & - & + & + & + & - \\
\hline Retinal pigmentation & + & - & - & - & + \\
\hline Cardiac arrhythmia & - & - & - & - & - \\
\hline Peptic ulceration & - & + & + & + & + \\
\hline \multicolumn{6}{|l|}{ CT Scan } \\
\hline Basal ganglia calcification & + & + & & + & + \\
\hline Cortical hypodensities & - & - & & + & - \\
\hline Cerebellar atrophy & - & - & & - & - \\
\hline Not done & & & + & & \\
\hline \multicolumn{6}{|l|}{ Muscle Biopsy } \\
\hline Positive & + & + & & & + \\
\hline Not done & & & + & + & \\
\hline
\end{tabular}

\section{Case histories}

Index case IV, 4

The proband presented in 1984, at the age of 13, complaining of a throbbing headache associated with nausea and vomiting. After admission to hospital she was observed to have a number of generalised tonic-clonic seizures. These were controlled with phenytoin. She had been mildly deaf for a number of years and was prone to constipation but otherwise had had no other medical problems before this admission. The patient was of small stature $(148 \mathrm{~cm})$ and slight build. She had no neurological signs apart from the deafness. A cranial CT scan showed calcification of the basal ganglia (fig 2).

Two months later she was readmitted with abdominal pain due to faecal impaction and within 24 hours became comatose. She was found to have a metabolic acidosis, hyponatraemia, and elevated serum pyruvate of 229 umol/1 (N 41-67) and lactate of $6.10 \mathrm{mmol} / 1$ (N 0.63-2.44). A CT scan showed hypodense areas in both cerebellar hemispheres and enlargement of the 4th ventricle and basal cisterns (fig 3). Cerebral digital subtraction angiography was normal and an EEG showed diffuse $0.5-1.5 \mathrm{~Hz}$ delta activity.

As the patient's conscious level improved over the next few weeks, marked truncal and gait ataxia and a coarse postural and intention tremor of the left upper limb were noted. Continuous myoclonic jerks were visible in the abdominal muscles. The cerebellar signs resolved within a few months but the myoclonic jerks have persisted ever since.

The patient was admitted to hospital on a number of occasions over the next two years with episodes of severe headache. On one occasion this was associated with a right homonymous hemianopia which persisted for several months but then resolved completely.

Table 1c Clinical, radiological and pathological features of the kindred

\begin{tabular}{|c|c|c|c|}
\hline Patient & $I I, 6$ & $I I, 7$ & $I, 1$ \\
\hline $\begin{array}{l}\text { Age at onset of major symptoms (y) } \\
\text { Age in } 1991 \text { of surviving members (y) } \\
\text { Age at death (y) }\end{array}$ & 60 & 56 & 75 \\
\hline $\begin{array}{l}\text { Neurological features } \\
\text { Stroke-like episodes } \\
\text { Status epilepticus: } \\
\text { Convulsive } \\
\text { Non-convulsive } \\
\text { Myoclonus } \\
\text { Cerebellar ataxia } \\
\text { Dementia } \\
\text { Myopathy } \\
\text { Headache/migraine } \\
\text { Neuropathy }\end{array}$ & $\begin{array}{l}- \\
- \\
- \\
- \\
- \\
- \\
-\end{array}$ & $\begin{array}{l}- \\
- \\
- \\
- \\
- \\
- \\
+ \\
-\end{array}$ & $\begin{array}{l}+1- \\
? \\
? \\
? \\
? \\
? \\
? \\
?\end{array}$ \\
\hline $\begin{array}{l}\text { Other clinical features } \\
\text { Short stature } \\
\text { Deafness } \\
\text { Diabetes } \\
\text { Constipation } \\
\text { Retinal pigmentation } \\
\text { Cardiac arrhythmia } \\
\text { Peptic ulceration }\end{array}$ & $\begin{array}{l}\overline{+} \\
\overline{+} \\
\overline{-} \\
\overline{-}\end{array}$ & $\begin{array}{l}\overline{+} \\
\overline{-} \\
\overline{-} \\
\overline{-}\end{array}$ & $\begin{array}{l}- \\
? \\
+ \\
? \\
? \\
? \\
+\end{array}$ \\
\hline $\begin{array}{l}\text { CT Scan } \\
\text { Basal ganglia calc } \\
\text { Cortical hypodensities } \\
\text { Cerebellar atrophy } \\
\text { Not done } \\
\text { Muscle Biopsy } \\
\text { Positive } \\
\text { Not done }\end{array}$ & $\bar{z}$ & $\begin{array}{l}+ \\
-\end{array}$ & + \\
\hline
\end{tabular}




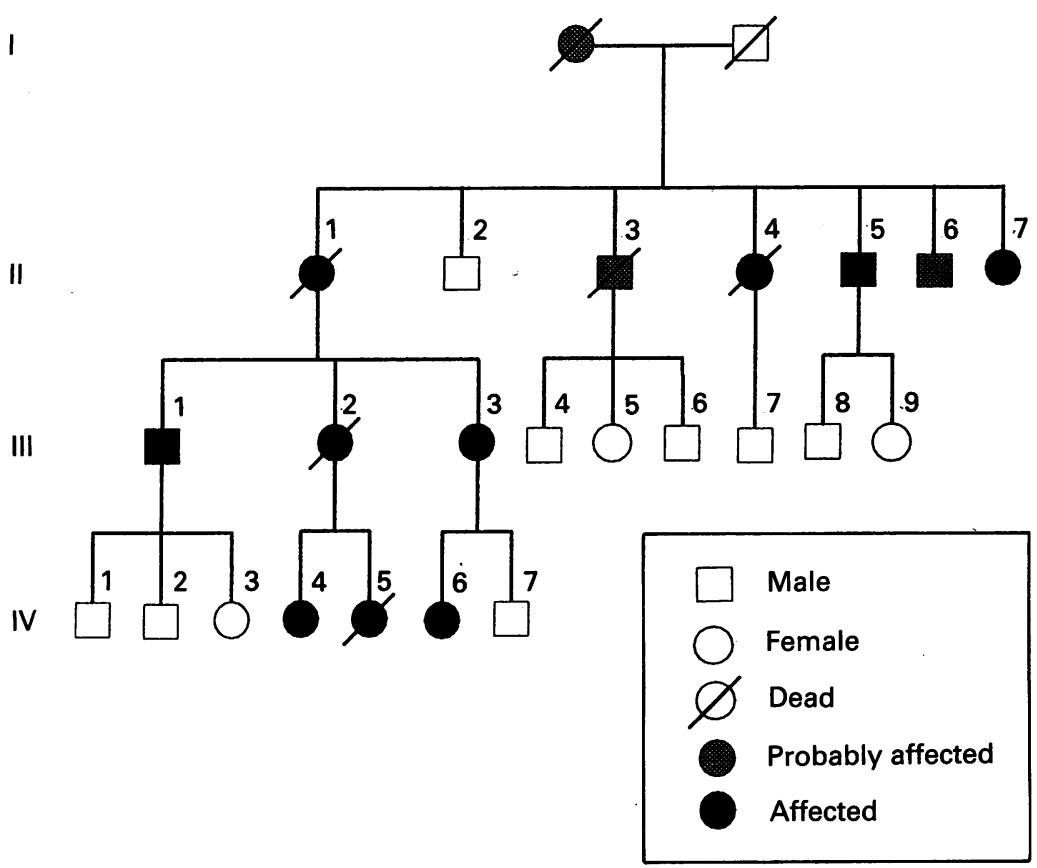

Figure 1 Family tree. Index case IV, 4.

Figure 2 Cerebral CT of index case showing prominent basal ganglio calcification.

Figure 3 Cerebral CT of the index case showing cerebellar atrophy and dilatation of 4 th ventricle.
Twice during 1986 she was readmitted for bowel pseudo-obstruction secondary to faecal impaction.

In 1988 the patient was readmitted with headache, vomiting and abdominal pain and, within a few hours, again became comatose. A CT scan showed a new hypodense area in the left parieto-occipital region. An EEG showed rhythmical generalised $2.5 \mathrm{~Hz}$ slow wave activity. The patient was treated with phenobarbitone on the basis that she was in non-convulsive status epilepticus. Her conscious level improved after a few days and she was then noted to have a severe global aphasia, mild right sided hemiparesis and a right homonymous hemianopia. These neurological signs almost completely resolved over the next few months.

Muscle biopsies performed in 1987 and 1988 showed no abnormalities. A third biopsy of the left deltoid muscle showed mild mitochondrial abnormalities (see below).

\section{Case III, 2}

This 43 year old female, the mother of the proband, was admitted to hospital in 1984 with a three day history of progressive, bifrontal, throbbing headaches and vomiting. On the day before admission she had had 4 episodes of loss of consciousness associated with jerking of the limbs. There was a long history of deafness, constipation and migraine. On examination, she was of small stature $(148 \mathrm{~cm})$ and had a left homonymous hemianopia.

A CT scan showed a low density lesion in the left parietal lobe, prominent basal ganglia calcification and dilatation of the fourth ventricle. Cerebral angiography was normal. Serum pyruvate was elevated at $103 \mu \mathrm{mol} / 1$ (N 41-67) as was the serum lactate which was $4 \cdot 10 \mu \mathrm{mol} / 1$ (N $0 \cdot 8-2 \cdot 6)$. Fasting blood glucose was raised at $11.0 \mu \mathrm{mol} / 1$ (N $2 \cdot 5-5 \cdot 5)$. The patient was treated with anticonvulsants and she improved within a few days.

She was readmitted two months later with profound lethargy, vertigo, dysphasia, severe headache, vomiting and confusion. An EEG showed rhythmical, generalised $2.5 \mathrm{~Hz}$ spike and wave activity. A diagnosis of non-convulsive status epilepticus was made and she was treated with anticonvulsants. She made a good recovery over the next few weeks.

Apart from continuing constipation, she was then well until December 1988 when she was readmitted with severe headache, followed, within a few hours, by coma. A repeat CT scan showed a hypodense lesion in the right temporo-parietal region. Her conscious level deteriorated and she died 10 days after admission.

\section{Case IV, 5}

This child, the sister of the proband, was admitted to hospital in 1973 at the age of three years with status epilepticus. This followed a three day febrile illness associated with vomiting. She was deeply comatose for two days. As her consciousness level 
improved over the next few days it was noted that she was blind. Pupillary responses were preserved suggesting that this was cortical blindness. Her sight returned to normal over the next four weeks. An EEG showed generalised slow wave activity. She had had a normal birth and development had been normal.

Over the next three years the patient had numerous admissions to hospital for status epilepticus, and episodes of dysphasia, right sided weakness, vomiting and throbbing frontal headache. In February 1978 she was noted to have an ataxic gait, intention tremor of both hands, mild right sided weakness and brisk reflexes with bilateral extensor plantar responses. An echocardiogram revealed mild mitral valve prolapse and an ECG showed the features of Wolff-Parkinson-White syndrome. Marked macular pigmentation was evident on fundoscopy. The serum lactate was 3-4 times the upper limit of the normal range.

In 1979 the patient stopped attending school because of progressive cognitive impairment and increasing lethargy. By the end of the year, she was unable to feed herself. A CT scan showed multiple low density lesions in both cerebral hemispheres, with dilatation of the ventricular system.

The patient's condition continued to deteriorate with dementia, lethargy, incontinence of urine and faeces, weakness, vomiting, headaches, and fits which became increasingly resistant to medication. The patient died in August 1982.

\section{MUSCLE BIOPSY FINDINGS}

Muscle morphology, histochemistry and biochemistry Open muscle biopsies were performed in eight patients of which seven were abnormal. Abnormalities varied in severity from minor changes (with only occasional fibres showing mitochondrial disorganisation or sub-sarcolemmal aggregation on succinate dehydrogenase and Gomorri trichrome stains) to marked changes (including generalised fibre atrophy with some fibres undergoing degeneration and up to $20 \%$ of the fibres showing

Table 2 Muscle biopsy biochemistry

\begin{tabular}{|c|c|c|c|c|c|}
\hline & \multicolumn{5}{|c|}{ Mitochondrial enzyme activity } \\
\hline & $\begin{array}{l}\text { Pyruvate } \\
\text { and Malate Cyt } \\
\text { "C" Reductase }\end{array}$ & $\begin{array}{l}\text { 2-Oxoglutarate } \\
\text { Cyt "C" } \\
\text { Reductase }\end{array}$ & $\begin{array}{l}\text { Glutamate } \\
\text { Cyt "C" } \\
\text { Reductase }\end{array}$ & $\begin{array}{l}\text { Succinate } \\
\text { Cyt “C" } \\
\text { Reductase }\end{array}$ & $\begin{array}{l}\text { Cytochrome } \\
\text { "C" Oxidase }\end{array}$ \\
\hline $\begin{array}{l}\text { Normal Range } \\
\mu \mathrm{mol} / \mathrm{min} / \mathrm{gm} \\
\text { of muscle }\end{array}$ & $0 \cdot 20-1$ & $0 \cdot 15-1$ & $0 \cdot 15-1$ & $3-10$ & $4-30$ \\
\hline $\begin{array}{r}\text { Patient: } \\
\text { IV, } 4 \\
\text { III, } 1 \\
\text { III, } 3 \\
\text { IV, } 6 \\
\text { II 1 }\end{array}$ & $\begin{array}{l}0.70 \\
0.72 \\
0.36 \\
0.57 \\
0.45\end{array}$ & $\begin{array}{l}0.18 \\
0.72 \\
0.50 \\
0.50 \\
0.46\end{array}$ & $\begin{array}{l}0.63 \\
0.28 \\
0.19 \\
0.30 \\
0.18\end{array}$ & $\begin{array}{l}2 \cdot 70 \\
0.72 \\
0.90 \\
0.20 \\
0.75\end{array}$ & $\begin{array}{l}8 \cdot 0 \\
3.9 \\
1.9 \\
2 \cdot 2 \\
2 \cdot 3\end{array}$ \\
\hline
\end{tabular}

Table 3 Serum pyruvate and lactate levels

\begin{tabular}{lllllll}
\hline Patient & $I I, 1$ & $I I I, 3$ & $I V, 6$ & $I V, 4$ & $I I I, 2$ & $I V, 5$ \\
\hline $\begin{array}{l}\text { Serum Lactate } \\
\quad \text { N 0.63-2.44 mmol/) }\end{array}$ & $1 \cdot 30$ & $1 \cdot 20$ & $1 \cdot 10$ & $6 \cdot 10$ & $4 \cdot 10$ & $7 \cdot 32$ \\
$\begin{array}{l}\text { Serum Pyruvate } \\
\quad \text { (N 41-67 } \mu \mathrm{mol} / \mathrm{l})\end{array}$ & 82 & 94 & 71 & 229 & 103 & - \\
\hline
\end{tabular}

mitochondrial abnormalities with glycogen and lipid accumulation on appropriate histochemical stains). Cytochrome C oxidase staining was performed on several of the more recent biopsies but did not yield additional information. The fibre type was of normal distribution.

Muscle biopsy abnormalities tended to be most marked in older patients (for example, case II, 5), rather than in those with severe clinical manifestations (such as, case IV, 4, the index case).

Mitochondrial mutation studies

The nt 3243 A-G MELAS mutation was detected in two cases examined (patients: II, 1 and IV, 4). There was no evidence of the alternative A-G MELAS mutation (nt 11084) or the A-G 8344 (MERRF) mutation in any of the cases. A full investigation of the mitochondrial genome in symptomatic and asymptomatic members of this family is now in progress and will be reported separately.

The results of the muscle biochemistry on crude extract are seen in table 2 . Four of the patients had cytochrome " $\mathrm{C}$ " oxidase deficiency.

Serum lactate and pyruvate levels

Table 3 shows the serum pyruvate and lactate levels for the group. Five patients had elevated pyruvate levels and three had elevated lactate levels.

\section{Muscle biopsy biochemistry}

In three patients a cytochrome $\mathrm{C}$ oxidase deficiency was demonstrated. One other patient had borderline cytochrome $\mathrm{C}$ oxidase deficiency. Normal mitochondrial enzyme activity was demonstrated in the other patients studied.

\section{Electron microscopy}

The muscle biopsies examined by electron microscopy showed abnormalities varying from severe to mild. Severe cases showed myofibrillar degeneration with patchy loss and thinning of the myofibrils and associated increase in glycogen; in these areas the mitochrondria tended to be pleomorphic. In some cases, there were increased numbers of lipid vacuoles and occasionally some dilatation of the sarcoplasmic reticulum. Some fibres had aggregates of mitochondria, pleomorphic and with inclusions, beneath the sarcolemmal membrane.

The inclusions were constant in appearance within this family and consisted of round, uniformly stained, moderately dense bodies without a limiting membrane or obvious internal structure. Paracrystalline or "parking lot" inclusions were not seen. The inclusions varied in number from case to case and correlated with the severity of the other changes. In the more severely affected cases, numerous mitochondria within an affected fibre would contain an inclusion, occasionally more than one; in the mildly affected cases only an occasional mitochondrion with an inclusion could be seen and then only after a careful search. 


\section{Discussion}

There seems little doubt of the diagnosis of mitochondrial encephalomyopathy in this family. Ten members had clinical features known to be associated with this disorder; a maternal pattern of inheritance could be shown over four generations; seven members had evidence of mitochondrial abnormalities on muscle biopsy; a mitochondrial point mutation was detected in the two cases which were examined. Of interest in this kindred is the diversity of clinical expression in members, all of whom presumably had the same mitochondrial mutation. The index case had episodes of status epilepticus associated with major neurological deficits beginning in adolescence. By contrast, the only clinical evidence of the disease in case III, 1, a man of middle age, was deafness and diabetes. In case II,5 myopathy, peripheral neuropathy, dementia and an extrapyramidal disorder had their onset in late middle age.

Severely affected patients had a distinctive presentation. Typically, an attack would begin with a severe, unilateral, throbbing headache associated with vomiting and in some cases constipation. Within 24-48 hours, the patients developed generalised tonicclonic seizures usually leading to status epilepticus. Two patients became comatose without preceding convulsions and were found, on electroencephalography, to be in non-convulsive status epilepticus (IV, 4 and III,2). On recovery of consciousness, a neurological deficit, such as homonymous hemianopia, dysphasia, hemiparesis or cerebellar ataxia, was apparent. The cerebral CT scan at this time revealed low density lesions which fitted no single vascular territory. These were not associated with cerebral or extracranial angiographic abnormalities, a finding consistent with other reports. ${ }^{13}$ The recovery from neurological deficits which, on both clinical and radiological grounds were severe, was often surprisingly good. In this kindred, acute neurological deficits were usually accompanied by fits. The term "stroke-like" episode, often used to describe such attacks ${ }^{78}$ does not convey an accurate picture of their presentation. Similarly, the epilepsy which occurs in these patients is unusual in that it is characterised by episodes of status epilepticus separated by relatively fit-free intervals. ${ }^{13}$

A number of patients within this kindred had features of mitochondrial encephalomyopathy which were not readily apparent Deafness was present in 11, basal ganglia calcification (on CT scanning) in eight, short stature in two, severe constipation in five, peptic ulceration in five, non-insulin dependent diabetes in six and migraine in five. Some of these features are common and therefore could be coincidental; all, however, appeared in a pattern consistent with mitochondrial inheritance and an association with $M E$, with the exception of peptic ulceration, has been described in previous studies. ${ }^{7813-15}$ It seems unlikely that the deafness was coincidental for it always began in childhood or early adulthood. Basal ganglia calcification occurs in only $0 \cdot 23-1 \cdot 6 \%$ of patients ${ }^{16-18}$ and non-insulin dependent diabetes in $1-2 \% .{ }^{19}$ The constipation which occurred in this kindred was severe enough in itself to warrant hospital admission in three patients (IV,4, II,3 and II,1). Patient II,1 had recurrent bouts of severe constipation beginning in her 30 s and culminating in death from pseudoobstruction of the bowel at the age of 78 . Severe constipation, associated with mitochondrial myopathy has been reported by others. ${ }^{20}$ Rather than listing these as associated features of mitochondrial encephalomyopathy it is probably more correct to view them as an integral part of a multi-system disease, a mitochondrial cytopathy.

There are difficulties in fitting this kindred into the current classification of mitochondrial encephalomyopathy. ${ }^{4821}$ The index case and patient IV,5 had features of MELAS: acute neurological deficits, epilepsy, lactic acidaemia and mitochondrial changes on muscle biopsy. The index case, however, also had myoclonus and cerebellar ataxia, features more consistent with MERRF. ${ }^{6}$ Patient IV,5 had retinal changes and a heart conduction defect, features associated with Kearns Sayre syndrome. ${ }^{4}$ The major manifestation of the disease in patient II, 5 was of a mitochondrial myopathy with proximal weakness, ptosis and external ophthalmoplegia. In addition, he had deafness, peripheral neuropathy, extrapyramidal signs and ataxia. In this kindred there was also marked variability in the age of onset of major symptoms; the youngest presented at three years, the oldest at 70 and four presented after the age of 40 .

Others have also been struck by the variability of clinical features and age of onset within a single kindred. In reviewing 90 patients with proven mitochondrial myopathy, Petty et $a l^{14}$ found marked overlap between clinical categories. The kindred of Shimogi et $a l^{22}$ had features of MELAS and mitochondrial myopathy. The overlap between MERFF and MELAS has been recognised by a number of authors ${ }^{515}$ including Fukuhara, who first described MERFF as a clinical entity. ${ }^{23}$ The variability of clinical expression of mitochondrial encephalomyopathy cannot be related to specific defects in the respiratory chain ${ }^{24-26}$ and remains the subject of speculation. ${ }^{27-30}$

The nt 3243 A-G mutation identified in this family is identical to that reported in the majority of MELAS families in Japan. ${ }^{10}$ It has also been encountered in at least one other Australian family. It is not present in all Australian cases; an alternative A-G transition mutation at nt 11084 has been identified in one MELAS family who lack the nt 3243 mutation. ${ }^{11}$

Mitochondrial encephalomyopathy is probably under-recognised, particularly in its minor manifestations. Many of its features are common and readily attributable to other causes. It should be considered in the following circumstances:

1) Major manifestations: patients presenting with an acute "stroke"-like episode with 
these additional features: a) status epilepticus, convulsive or non-convulsive; b) onset in childhood or early adulthood; c) familial deafness and/or diabetes mellitus d) short stature; e) severe headache, vomiting and constipation; $f$ ) calcification of the basal ganglia on CT scan.

2) Minor manifestations: patients presenting with one or more of the following constellation: a) familial deafness; b) diabetes mellitus; c) intractable constipation; d) myopathy (a major manifestation in some patients); e) possibly migraine and familial peptic ulceration.

Having considered the diagnosis, confirmation depends upon the demonstration of abnormal mitochondria on muscle biopsy, or identification of a mitochondrial DNA mutation. Unfortunately, as exemplified by the proband, the patchy distribution of the abnormality may lead to a negative result on muscle biopsy. Paradoxically, muscle abnormalities may be most striking in older patients some of whom have only minor manifestations of the disease.

1 Leigh D. Subacute necrotizing encephalomyelopathy in an infant. $\mathcal{f}$ Neurol Neurosurg Psychiat 1951;14:216-21.

2 Alpers B. Diffuse progressive degeneration of the grey matter of the cerebrum. Arch Neurol Psychiatry 1931;25:469-505.

3 Gabetti P, Mellman W, Gonatas N. Familial spongy degeneration of the central nervous system (Von Bogaert-Bertrondt disease). Acta Neuropathol 1969;12: 103-8.

4 Kearns TP, Sayre GP. Retinitis pigmentosa, external ophthalmoplegia and complete heart block: unusual synthalmoplegia and complete heart block: unusual syndrome with histologic study
Opthalmol 1958;60:280-9.

5 Rowland LP, Hays AP, Dimauro S, De Vivo DC, Behrens M. Diverse clinical disorders associated with morphological abnormalities of mitochondria. In: Scarlato $G$ Cervi C, eds. Mitochondrial pathology in muscle diseases. Padua, Italy: Piccin Medical Books, 1983:212-8.

6 Fukuhara N, Tokiguchi S, Shirakawa K, Tsubaki T. Myoclonus epilepsy associated with ragged red fibres (mitochondrial abnormalities): disease entity or syndrome? Light and electron microscopic studies of two cases and a review of the literature. Fournal of Neurol Sciences 1980;47:117-33.

7 Pavlakis SG, Phillips PC, Dimauro S, De Vivo DC, Rowland LP. Mitochondrial myopathy, encephalopathy, Rowland LP. Mitochondrial myopathy, encephalopathy, lactic acidosis and stroke like episodes: a distrome. Ann Neurol 1984;16:481-8.

8 Di Mauro S, Bonilla E, Zeviani M, Nakagawa M, De Vivo DC. Mitochondrial myopathies. Ann Neurol 1985;17: 521-38.

9 Edwards RHT, Round JM, Jones DA. Needle biopsy of skeletal muscle: a review of 10 years experience. Muscle Nerve 1983;6:676-83.
10 Goto Y, Nonaku I, Horai S. A mutant in the tRNA leucine gene associated with the MELAS subgroup of mitochondrial encephalomyopathies. Nature 1990;348: 651-3.

11 Lertrit $\mathrm{P}$, Noer AS, Jean-Francis MIB, et al. A new disease related mutation for mitochondrial encephalomyopathy, related mutation for mitochondrial encephalomyopathy, ing the ND4 subunit of complex I. Am $f$ Human ing the ND4 subunit of

12 Noer AF, Sudoyo $H$, Lertrit $P$, Thyarajun $D$, Utthariaphol RP, Kapsa R, Byrne E, Marzuki S. tRNA mutation in mitochondrial DNA is the causative genetic lesion underlying Myoclonic Epilepsy and Ragged Red Fibre syndrome. Am $\mathcal{F}$ Human Genetics 1991;49:715-22.

13 Montagna $P$, Gallassi $R$, Medori $R$, et al. MELAS syndrome: Characteristic migrainous and epileptic features and maternal transmission. Neurology 1988;38:751-4.

14 Petty RKH, Harding AE, Morgan-Hughes JA. The clinical features of mitochondrial myopathy. Brain clinical features

15 Peterson PL, Martens ME, Lee CP. Mitochondrial encephalomyopathies. Neurol Clinics 1988;6:529-44.

16 Cegido A, Zimmerman R, Packer R, Balinuk L, Seigal K, Dangio $G$. Significance of basal ganglia calcification in children. Pediatr Neurosci 1988;14:64-70.

17 Murphy M. Clinical correlations of CT scan detected calcifications in the basal ganglia. Ann Neurol 1979;6: 507-11.

18 Harrington MG, Macpherson P, Mcintosh WB, Allam $B F$, Bone I. The presence of the incidental finding of basal ganglia calcification on computerised tomography. f Neurol Neurosurg Psychiatry 1981;44:1168-70.

19 Unger RH, Foster DW. Diabetes Mellitus. In: Wilson JD, Foster DW, eds. William's textbook of endocrinology; 8th ed. Philadelphia: Saunders, 1990;1739-59.

20 Cervera R, Bruix J, Bayes A, Blesa R, Illa I, Coll J, CarciaPuges AM. Chronic intestinal pseudo-obstruction and ophthalmoplegia in a patient with mitochondrial myopathy Gut 1988:29:544-7.

21 Driscoll P, Larsen PD, Gruber AB. MELAS syndrome involving a mother and two children. Arch Neurol 1987;44:971-3.

22 Shimoji A, Katsuragi S, Miyakawa T, Hira R, Watanabe K, Miyakawa K, Ishitsu T, Miike T. Familial mitochondrial encephalomyopathy with stroke like episodes and episodic disturbances of consciousness. A study of a pedigree including three generations with multisystemic pedigres in 1987;41:1:47-55.

23 Fukuhara N. Stroke-like episodes in MERRF. Ann Neurol 1985;18:368.

24 Riggs JE, Schochet SS, Fakades AV, et al. Mitochondrial encephalomyopathy with decreased succinatecytochrome C reductase activity. Neurology 1984;34: 48-53.

25 Di Mauro S, Hays AP, Eastwood AB. Different clinical expressions of cytochrome " $C$ " oxidase deficiency. In: Scarlato G, Cerri C, eds. Mitochondrial pathology in muscle diseases. Padua, Italy: Piccin Medical Books, 1983,112-29.

26 Di Mauro S, Zeviani M, Servidei S, et al. Cytochrome oxidase deficiency: Clinical and biochemical heterogeneity. Ann NY Acad S $i$ 1986;488:19-32.

27 Kroon A, Van den Bogert. Biogenesis of mitochondria and genetics of mitochondrial defects. $\mathcal{F}$ Inherit Metab and genetics of mitoch

28 Darley-Usmar V. The molecular aetiology of human mitochondrial myopathies. Biochem Soc Trans 1987;15:102.

29 Schon EA, Rizzuto R, Moraes CT, Nakase H, Leuiani M, Schon EA, Rizzuto $R$, Moraes CT, Nakase H, Leuiani M,
Dimauro S. A direct repeat is a hotspot for large scale deletion of human mitochondrial DNA. Science 1989;244:346-9.

30 Grivel LA. Small, beautiful and essential. Nature 1989;341:569-71. 